\title{
Family Physicians' Perception of the New mRNA COVID-19 Vaccines
}

\author{
Samuel Ofei-Dodoo, PhD, MPA, MA, Rick Kellerman, MD, and Taylor Russell, MD
}

Introduction: This study was conducted to assess family physicians' perception of the US Food and Drug Administration-approved mRNA Coronavirus disease 2019 (COVID-19) vaccines, their plans to be vaccinated with an approved mRNA COVID-19 vaccine, and their support for vaccination of patients and family members.

Methods: The authors conducted a cross-sectional survey of $\mathbf{3 0 7}$ practicing family physicians, fulltime faculty physicians, and resident physicians in Kansas from December 14, 2020, to December 31, 2020. The study participants completed an anonymous, 20-item survey assessing family physicians' concerns about exposure to COVID-19 and their perceptions of the mRNA COVID-19 vaccines to control SARS-CoV-2. A mixed-method approach was used to collect, analyze, and interpret the data.

Results: There was a $51.1 \%$ response rate. The proportion of family physicians who reported their intentions to be vaccinated for COVID-19 was significantly higher than those who were hesitant to receive the mRNA vaccines $\left(90.6 \%\right.$ vs $\left.9.4 \% ; \chi^{2}[1, \mathrm{n}=307]=201.9 .1 ; P<.0001\right)$. Among those who were willing to be vaccinated with an approved mRNA COVID-19 vaccine, the main reasons were to prevent COVID-19 infection; protect self, family, and community; contribute to herd immunity; inspire confidence that the vaccines are safe and end the pandemic and bring life back to normal.

Conclusion: Our findings suggest a significantly positive association between a physician's concerns and their willingness to be vaccinated with an approved mRNA COVID-19 vaccine. With the authorization of 2 new mRNA COVID-19 vaccines, future studies should investigate the number of physicians in our study who received the vaccine. (J Am Board Fam Med 2021;34:898-906.)

Keywords: COVID-19, Cross-Sectional Studies, Family Medicine, Family Physicians, Herd Immunity, Kansas, mRNA, Pandemics, Surveys and Questionnaires, Vaccines

\section{Introduction}

Since its introduction into the human population in late 2019, the novel severe acute respiratory syndrome coronavirus 2 (SARS-CoV-2) has spread rapidly with vast global implications. By January 9, 2021, over 87 million total confirmed cases of Coronavirus disease 2019 (COVID-19) and over 1.9 million confirmed deaths had been reported globally, with the

This article was externally peer reviewed.

Submitted 5 February 2021; revised 27 April 2021; accepted 13 May 2021.

From the Department of Family and Community Medicine, University of Kansas School of Medicine-Wichita, Wichita, KS (SO-D); Department of Family and Community Medicine, University of Kansas School of Medicine-Wichita (RK); Family Medicine Residency at Via Christi Hospitals, University of Kansas School of Medicine-Wichita (TR).

Funding: None.

Conflict of interest: None.

Corresponding author: Samuel Ofei-Dodoo, PhD, MPA, MA, Department of Family and Community Medicine, University of Kansas School of Medicine-Wichita, 1010 N. Kansas, Wichita, KS 67214, Telephone: 316-293-1879, Fax: 316-293-2696 (E-mail: sofeidodoo@kumc.edu).
United States alone accounting for 22,102,069 confirmed cases and 371,084 deaths. ${ }^{1,2}$ The number of cases began to rise sharply in Midwestern states during November 2020, affecting cities and small towns, with daily case rates surpassing 4,600 per 100,000 people in the state of Kansas, compared with just over 2,000 per 100,000 at the beginning of October $2020 .^{2}$ Health care professionals, including those in primary care specialties such as family medicine, are among those working on the frontlines in response to the COVID-19 pandemic., ${ }^{3,4}$

As the world struggles with the widespread infection, the scientific community has raced to find answers to control the spread and devastating consequences of the SARS-CoV-2. On December 11, 2020, and December 18, 2020, the US Food and Drug Administration (FDA) issued emergency use authorization (EUA) for Pfizer-BioNTech and Moderna mRNA COVID-19 vaccines, respectively for the prevention of severe symptoms of COVID19 in individuals 16 years and older. ${ }^{5,6}$ The EUA 
allowed the vaccines to be distributed and used in the United States. Despite the unprecedented efforts by the scientific community to ensure that the vaccines were safe and efficacious, the widespread uptake of the COVID-19 vaccination had been undermined by vaccine hesitancy, similar to prior studies about vaccines where there was variable and inconsistent compliance. ${ }^{7-12}$ Successful immunization programs require widespread public education campaigns by trusted stakeholders, such as primary care physicians. Prior studies have shown that physicians are the most trusted source of immunization information, ${ }^{12-15}$ suggesting that physicians are a valuable source of knowledge to drive acceptance of the approved mRNA COVID19 vaccines. In addition to educating patients about the safety and efficacy of the approved mRNA COVID-19 vaccines, vaccination of health care providers is important in controlling the spread of the virus and role-modeling vaccine acceptance.

Given that physicians are a trusted source of information about vaccine acceptance, the purposes of this study were to assess family physicians' perception of the FDA approved mRNA COVID-19 vaccines, their plans to be vaccinated with an approved mRNA COVID-19 vaccine, and their support for vaccination of patients and family members. We evaluated the concerns family physicians have about themselves, family, and patients becoming infected with COVID-19. We hypothesized that the family physicians' concerns about their personal risk of acquiring COVID-19 infections would directly relate to their compliance with personally receiving an approved mRNA COVID-19 vaccine.

\section{Methods}

\section{Study Design and Participants}

This study was a cross-sectional survey of practicing family physicians, full-time faculty physicians, and resident physicians of the 3 family medicine residencies sponsored by the University of Kansas School of Medicine-Wichita (KUSM-W) Department of Family and Community Medicine (DFCM). The questionnaire focused on physician perceptions of the FDA-authorized COVID-19 vaccines used to prevent severe symptoms of SARS-CoV-2 infection. The study used a mixed-method approach to collect, analyze, and interpret the data. ${ }^{16}$ The quantitative approach allowed the authors to obtain valuefree and objective insights into the respondents' opinions about the mRNA COVID-19 vaccines. In contrast, the qualitative approach allowed for an indepth understanding of those insights. The KUSM Institutional Review Board approved the study.

\section{Study Instrument and Data Collection Process}

We used a 20-item questionnaire (Appendix) to assess family physicians' concerns about exposure to COVID-19 and their perceptions of the FDA authorized mRNA COVID-19 vaccines to control SARS-CoV-2. Several information sources were used to generate and select the questions. First, the questions were created based on study goals. The generated questions were reviewed by a family physician and a research scientist to ensure that the questions had face validity. The questionnaire was hosted on SurveyMonkey ${ }^{\circledR}$ (SVMK Inc., San Mateo, CA), a secure web-based survey system. A generated link to the 20 -item survey was sent via email to 601 potential participants. We utilized an email system called FM-RADIO (Family Medicine Research And Data, Information, and Outcomes Practice-Based Research Network) as a survey collection tool. The FM-RADIO is an electronic practice-based research network comprised of actively practicing family physicians throughout the state of Kansas who are KUSM-W family medicine residency program graduates, family physician nonKUSM-W graduates, faculty physicians, and resident physicians. The potential participants were on the FM-RADIO list.

As a standard practice, the physicians who opened 1 of 3 e-mail invitations were considered to have received the invitation to participate in the study. ${ }^{17-19}$ Overall, 375 physicians opened at least 1 of the e-mail invitations and were considered to have received the invitation to participate. Participation was voluntary, and responses were anonymous. Data collection occurred from December 14, 2020, to December 31, 2020. No compensation was provided to participants.

\section{Statistical Analyses \\ Quantitative Data}

Standard descriptive statistics were used to create a demographic profile of the respondents. Associations between the variables were evaluated using a Likelihood-Ratio (or Fisher exact test when cell sizes were $<5$ ). For statistical analysis purposes, the respondents' perceived concerns about becoming infected with COVID-19 were clustered into 3 groups 
(extreme concern, moderate concern, and slight concern [combination of somewhat, slightly, and not at all concerned]). Then the Likelihood-Ratio test was used to evaluate the relationship between the clustered concern groups and family physicians' decisions to receive an approved mRNA COVID-19 vaccine (yes/no [combination of maybe and no responses]). A sample size of 100 was calculated as necessary for adequate power $(>0.85)$ to detect significant relationships among the variables with 2 degrees of freedom, $P<.05$, and 0.3 effect size. ${ }^{20,21}$ All quantitative analyses were 2 -sided with $\alpha$ of 0.05 . The IBM SPSS (Statistical Package for the Social Sciences), version 26 , was used for these analyses.

\section{Open-Ended Responses}

The study team used an immersion-crystallization approach $^{16,22-25}$ to analyze the content of openended responses individually and in a group meeting. The immersion-crystallization approach offers researchers the opportunity to examine collected data in detail and periodically suspend the immersion process to reflect on emerging findings until consistent themes are identified. ${ }^{16,24}$ This multidisciplinary team was composed of a health psychologist (SO-D), a family physician (RK), and a family medicine resident (TR).

\section{Results}

\section{Respondent Characteristics}

Of the 375 family physicians who opened the e-mail invitation, 307 completed all or most of the survey for a participation rate of $69.2 \%$. Of the 601 potential participants, 307 responded to the survey for a response rate of $51.1 \%$. Table 1 represents the demographic information of the respondents. The average age of respondents was 46.6 years (standard deviation, 13.1 ), $54.9 \%$ were male, $76.4 \%$ were practicing physicians, and $46.5 \%$ practiced primarily in Sedgwick County; all others practiced in a total of 51 counties in Kansas. Slightly over 11\% reported that they had either received a positive COVID-19 test or were diagnosed with COVID-19. Just over $90 \%$ of the respondents expressed their intentions to be vaccinated for COVID-19. There was a $\pm 4.69 \%$ margin of error at a $95 \%$ confidence level between the study sample and the population of all family physicians in Kansas, demonstrating that our sample generally represented the population of family physicians in Kansas. ${ }^{26}$
Table 1. Respondent Characteristics $(\mathrm{N}=307)$

\begin{tabular}{|c|c|}
\hline Characteristics & $\begin{array}{c}\text { All } \\
\text { Respondents }\end{array}$ \\
\hline Biological sex at birth, n (\%) & $(\mathrm{n}=286)$ \\
\hline Male & $157(54.9)$ \\
\hline Female & $129(45.1)$ \\
\hline Age & $(\mathrm{n}=280)$ \\
\hline Mean $\pm \mathrm{SD}, \mathrm{y}$ & $46.6 \pm 13.1$ \\
\hline Median & 44 \\
\hline Minimum & 26 \\
\hline Maximum & 85 \\
\hline Career status, n (\%) & $(\mathrm{n}=292)$ \\
\hline Practicing family physician & $223(76.4)$ \\
\hline Full-time faculty & $31(10.6)$ \\
\hline Resident-physicians & $38(13.0)$ \\
\hline $\begin{array}{l}\text { Practicing physician/full-time faculty years in clinical } \\
\text { practice }\end{array}$ & $(\mathrm{n}=252)$ \\
\hline Mean $\pm \mathrm{SD}, \mathrm{y}$ & $17.0 \pm 12.1$ \\
\hline Median & 15 \\
\hline Minimum & $<1$ \\
\hline Maximum & 57 \\
\hline Medical trainees, n (\%) & $(\mathrm{n}=37)$ \\
\hline First-year residents & $14(37.8)$ \\
\hline Second-year residents & $10(27.0)$ \\
\hline Third-year residents & $13(35.1)$ \\
\hline $\begin{array}{l}\text { Kansas county where the physicians primarily practiced, } \\
\text { n (\%) }\end{array}$ & $(\mathrm{n}=284)$ \\
\hline Butler & $14(4.9)$ \\
\hline Douglas & $6(2.1)$ \\
\hline Ford & $5(1.8)$ \\
\hline Harvey & $10(3.5)$ \\
\hline McPherson & $11(3.9)$ \\
\hline Riley & $6(2.1)$ \\
\hline Saline & $14(4.9)$ \\
\hline Sedgwick & $132(46.5)$ \\
\hline Other & $86(30.3)$ \\
\hline $\begin{array}{l}\text { Received a positive COVID-19 test or diagnosed with } \\
\text { COVID-19, n (\%) }\end{array}$ & $(\mathrm{n}=306)$ \\
\hline Yes & $35(11.4)$ \\
\hline No & $270(88.2)$ \\
\hline I don't know & $1(0.4)$ \\
\hline \multicolumn{2}{|l|}{$\begin{array}{l}\text { Intend to be vaccinated with an approved mRNA } \\
\text { COVID-19 vaccine, } \mathrm{n}(\%)\end{array}$} \\
\hline Yes & $278(90.6)$ \\
\hline No & $5(1.6)$ \\
\hline Maybe & $24(7.8)$ \\
\hline $\begin{array}{l}\text { Recommend an approved mRNA COVID-19 vaccine } \\
\text { to family, no (\%) }\end{array}$ & $(\mathrm{n}=296)$ \\
\hline Yes & $268(90.5)$ \\
\hline No & $6(2.0)$ \\
\hline Maybe & $22(7.4)$ \\
\hline $\begin{array}{l}\text { Recommend an approved mRNA COVID-19 vaccine } \\
\text { to patients, no (\%) }\end{array}$ & $(n=293)$ \\
\hline Yes & $278(94.9)$ \\
\hline No & $0(0)$ \\
\hline Maybe & $15(5.1)$ \\
\hline
\end{tabular}

SD, standard deviation. 
Table 2. Respondents' Concerns About the CoVID-19 Infection $(\mathrm{N}=307)$

\begin{tabular}{ll}
\hline Level of Concern & \multicolumn{1}{c}{ All } \\
Respondents
\end{tabular}

\section{Quantitative Results}

The proportion of family physicians who reported their intentions to be vaccinated for COVID-19 was significantly higher than those who were hesitant to receive the mRNA vaccines $(90.6 \%$ vs $9.4 \%$; $\left.\chi^{2}[1, \mathrm{n}=307]=201.9 .1 ; P<.0001\right)$. Respondents listed several reasons for their decisions. In addition, the proportion of family physicians who would recommend an approved COVID-19 vaccine to patients was significantly higher than those who were hesitant to recommend the vaccine $(94.9 \%$ vs $\left.5.1 \% ; \chi^{2}[1, \mathrm{n}=293]=237.1 ; P<.0001\right)$.
As Table 2 shows, $73 \%$ of the respondents reported extreme/moderate concern that they would personally become infected with COVID19. Fisher exact test showed a significant association between respondents' perceived concerns about personally becoming infected with COVID-19 and their decision to be vaccinated with an approved mRNA COVID-19 vaccine $\left(\chi^{2}[2, \mathrm{n}=307]=13.35\right.$; $P<.01$; Cramer's $V=0.21$; Table $3 \mathrm{a}$ ). As shown in Table 3b, follow-up pairwise comparisons showed significant pairwise differences between the clustered extreme concern group and the slight concern group and between the moderate concern group and the slight concern group. The greater the level of concern about personal exposure to COVID-19, the more likely a family physician's intention to be vaccinated for COVID-19.

\section{Qualitative Results}

Family Physicians Who Intend to Be Vaccinated with an Approved COVID-19 Vaccine

Nearly $91 \%$ of 307 respondents reported their intention to be vaccinated with an approved mRNA COVID-19 vaccine. Seven themes about support for the COVID-19 vaccination emerged from the qualitative analyses: prevent COVID-19 infection; protect self, family, community; contribute to herd immunity; inspire confidence that the vaccines are safe; end the pandemic and bring life to normal; belief in science and vaccine safety; and the vaccine is less risky than contracting COVID (Table 4a).

Family Physicians Who Were Resistant to Be Vaccinated with an Approved mRNA COVID19 Vaccine

Nearly $8 \%$ of 307 respondents indicated their hesitancy to receive the approved mRNA COVID-19

Table 3a. Relationship Between Respondents' Perceived Concerns About Becoming Infected with COVID-19 and Decision To Be Vaccinated with an Approved mRNA COVID-19 Vaccine

\begin{tabular}{|c|c|c|c|c|c|c|}
\hline \multirow[b]{2}{*}{ Measures } & \multicolumn{3}{|c|}{$\begin{array}{c}\text { Intention To Be Vaccinated with an } \\
\text { Approved mRNA COVID-19 }\end{array}$} & \multirow[b]{2}{*}{ Pearson $\chi^{2}$} & \multirow[b]{2}{*}{$P$ value } & \multirow[b]{2}{*}{ Cramer's $V$} \\
\hline & Yes & No & Total & & & \\
\hline Level of concern, n (\%) & & & & 13.35 & $<0.001$ & 0.21 \\
\hline Extreme concern & $74(96.1)$ & $3(3.9)$ & $77(100)$ & & & \\
\hline Moderate concern & $137(93.2)$ & $10(6.8)$ & $147(100)$ & & & \\
\hline Slight concern & $67(80.7)$ & $16(19.3)$ & $83(100)$ & & & \\
\hline Total & $278(90.6)$ & $29(9.4)$ & $307(100)$ & & & \\
\hline
\end{tabular}


Table 3b. Results for Pairwise Comparison Using the Holm Sequential Bonferroni Method

\begin{tabular}{llll}
\hline Comparisons & Pearson $\chi^{2}$ & $P$ value $(\boldsymbol{\alpha})$ & Cramer's $V$ \\
\hline Moderate concern vs slight concern & $8.23^{*}$ & $.004(0.017)$ & 0.189 \\
Extreme concern vs slight concern & $9.03^{*}$ & $.031(0.025)$ & 0.238 \\
Extreme concern vs moderate concern & 0.78 & $.55(0.050)$ & 0.059 \\
\hline
\end{tabular}

${ }^{*} P$ value $\leq \alpha$.

Table 4a. Open-Ended Comments on Reasons Family Physicians' Intend to Receive an Approved mRNA COVID-19 Vaccine

\begin{tabular}{|c|c|}
\hline Themes & Quotes from Participants \\
\hline \multirow[t]{2}{*}{ Prevent COVID-19 infection } & "Vaccination is our best defense against the pandemic." \\
\hline & $\begin{array}{l}\text { "I have seen the horrors of COVID-19 firsthand and believe it is critically important to do all we } \\
\text { can as a community to focus on prevention." }\end{array}$ \\
\hline \multirow[t]{2}{*}{ Protect self, family, community } & "Because it is an important part of protecting those around me." \\
\hline & "I want to protect myself, my family, and my patients." \\
\hline \multirow[t]{2}{*}{ Contribute to herd immunity } & "I think the vaccination is the socially responsible thing to work towards herd immunity." \\
\hline & $\begin{array}{l}\text { "Herd immunity is important for public health and is our way to loosened restrictions but } \\
\text { cannot be accomplished without vaccinations." }\end{array}$ \\
\hline \multirow{2}{*}{$\begin{array}{l}\text { Inspire confidence that the } \\
\text { vaccines are safe }\end{array}$} & "To set a good example for family, friends, patients, and coworkers that the vaccine is safe." \\
\hline & $\begin{array}{l}\text { "It is safe and the right thing to do to end the pandemic. Medical personnel need to set the } \\
\text { example." }\end{array}$ \\
\hline \multirow{2}{*}{$\begin{array}{l}\text { End the pandemic and bring life } \\
\text { to normal }\end{array}$} & "Widespread vaccination is the only way we end the pandemic." \\
\hline & $\begin{array}{l}\text { "I'm excited that my action may help us return to something that looks more normal in the } \\
\text { world." }\end{array}$ \\
\hline \multirow{2}{*}{$\begin{array}{l}\text { Belief in science and vaccine } \\
\text { safety }\end{array}$} & [I] "feel appropriate research as even one at this point to prove the vaccine's safety." \\
\hline & $\begin{array}{l}\text { "I'm going to look into the science of the vaccine. But the high efficacy reported makes it } \\
\text { enticing." }\end{array}$ \\
\hline \multirow{2}{*}{$\begin{array}{l}\text { Vaccine is less risky than } \\
\text { contracting COVID }\end{array}$} & "Risk of vaccine side effects lower than potential complications of COVID." \\
\hline & "I feel the risk of the vaccine is less than the risk of getting COVID." \\
\hline
\end{tabular}

vaccines. Four themes emerged from the qualitative analyses: concerns about safety and adverse side effects, previous COVID-19 infection, low risk, and other reasons (Table $4 b$ ).

Only 5 of 307 (1.6\%) respondents indicated their outright refusal of the approved mRNA COVID19 vaccines because they just "do not want it."

\section{Discussion}

Our study has demonstrated that family physicians in Kansas have a positive perception of the approved mRNA COVID-19 vaccines as safe and efficacious against COVID-19 infections. A significantly high proportion $(90.6 \%)$ of the physicians expressed their intention to receive an approved mRNA COVID19 vaccination. Among those who were willing to be vaccinated with an approved mRNA COVID-19 vaccine, the main reasons were to prevent spread of the infection; protect self, family, and others against COVID-19; contribute to herd immunity; and end the pandemic. Interestingly, several physicians indicated that they intended to be vaccinated with the mRNA COVID-19 vaccine to inspire confidence that the vaccine is safe, a reason consistent with recommended strategies to drive vaccine acceptance. ${ }^{13}$

Only $1.6 \%$ of physicians expressed their outright rejection of the vaccines because they simply did not want the vaccination. The reasons for objection to COVID-19 vaccination by family physicians were consistent with prior studies documenting vaccination hesitancy among different populations. ${ }^{12,27,28}$

Nearly $8 \%$ of physicians indicated their hesitancy to receive the vaccine for various reasons, including concerns about safety and adverse side effects, existing immunity due to prior COVID-19 infections, pregnancy, and breastfeeding. While concerns are 
Table 4b. Open-Ended Comments on Reasons Family Physicians Are Resistant to Receiving an Approved mRNA COVID-19 Vaccine

\begin{tabular}{|c|c|}
\hline Themes & Quotes from Participants \\
\hline \multirow[t]{2}{*}{ Concerns about safety and adverse side effects } & "Concerns for detrimental long-term side effects." \\
\hline & $\begin{array}{l}\text { "Don't have enough information about the adverse effects of the } \\
\text { vaccination." }\end{array}$ \\
\hline \multirow[t]{2}{*}{ Previous COVID-19 infection } & $\begin{array}{l}\text { "Just had COVID. I most likely immune. May consider in the } \\
\text { fall." }\end{array}$ \\
\hline & $\begin{array}{l}\text { "I must getting over COVID myself. I would wait at least } 90 \text { days } \\
\text { to consider getting it for myself." }\end{array}$ \\
\hline \multirow[t]{2}{*}{ Low-risk group } & $\begin{array}{l}\text { "I feel that I'm still young and healthy and statistically have a good } \\
\text { chance of not having significant disease." }\end{array}$ \\
\hline & $\begin{array}{l}\text { "Low risk of getting infected with COVID, waiting to see } \\
\text { firsthand how people do with the vaccination." }\end{array}$ \\
\hline \multirow[t]{3}{*}{ Other reasons } & "Hesitation due to breastfeeding." \\
\hline & "Pregnancy." \\
\hline & "Previous significant reaction to MMR vaccine." \\
\hline
\end{tabular}

understandable, the FDA, the Centers for Disease Control and Prevention (CDC), and the Advisory Committee on Immunization Practices have reviewed data on the two mRNA COVID-19 vaccines and determined them to be safe and effective in reducing potential infection with COVID-19 among individuals 16 years of age and older. ${ }^{29-34}$ Subsequent studies have shown that the approved mRNA COVID-19 vaccines are safe and effective in preventing severe COVID-19 illness among individuals 16 years and older. $^{34-36}$

Regarding hesitancy due to pregnancy and breastfeeding, the CDC, the American College of Obstetrics and Gynecology, and the Society for Maternal-Fetal Medicine recommend that the approved mRNA COVID-19 vaccines should be offered to pregnant and breastfeeding individuals, even though there are limited data about the safety of the vaccines for this population subset. ${ }^{29,37-39}$ Some physicians who were hesitant to receive the approved mRNA COVID-19 vaccines assumed they have natural immunity to the infection due to a prior COVID-19 infection. There is a lack of complete data on the duration of immunity provided by natural infection or vaccination. ${ }^{30,31}$ While more data are being collected; the CDC advises that both natural and vaccine-induced immunity are important to control the spread of COVID-19 infection. ${ }^{30}$ More efforts to overcome perceived barriers to the approved mRNA COVID-19 vaccines are needed.

Physician perception of the positive benefits and safety of the approved mRNA COVID-19 vaccines may improve the general public's confidence in the vaccine, especially for those who are unsure about safety and effectiveness and may encourage the public to be vaccinated against COVID-19.27,28 This is especially relevant given that physicians are regarded as a trusted source of vaccination information. ${ }^{12-15,40}$

We hypothesized that the family physicians' concerns about their personal risk of exposure to COVID19 infections would encourage compliance with personally receiving the approved mRNA COVID-19 vaccines. Our findings showed that a high proportion of the physicians were extremely/moderately concerned about becoming infected and subsequently infecting patients and family members. These concerns have been expressed by other frontline health care providers battling the pandemic..$^{33,41-43}$ Our findings suggest a significantly positive association between a physician's concerns and their willingness to be vaccinated with an approved COVID-19 vaccine. This finding makes sense given that family physicians are working on the frontline of the pandemic, have a high risk of contracting COVID-19, and witness the devastating consequences of COVID-19. 3,27,41,42 Vaccinations prevent both viral infections and illnesses. ${ }^{43,44}$ One way to slow down the spread of COVID-19 infections and return to some sense of normalcy is through the COVID-19 vaccinations. Family physicians' positive perception of the mRNA COVID-19 vaccines, their intention to receive, and their advocacy for the vaccines should be reassuring to the public.

\section{Study Limitations}

Our study has limitations. The survey presents a snapshot of the physicians' subjective responses. The survey instrument was not previously validated, but 
measures were taken to ensure that it has face validity. In addition, the study relied on self-reported data collected in the form of an online survey and may have been influenced by recall and selection biases. As this is a cross-sectional study, we could not establish a causal relationship between concerns about personally contracting COVID-19 and respondent intention for COVID-19 vaccination; nor can we know whether one preceded the other. Additional research is warranted. Finally, the study population was limited to a specific geographic area, though, for the purposes of this study, family physicians in Kansas were the target population.

As the world continues to grapple with the pandemic, COVID-19 vaccination is the next and necessary step to protect Americans, reduce the impact of the pandemic, and return life to normal. The high proportion of surveyed physicians willing to be vaccinated against COVID-19 is encouraging and should be reassuring to the public regarding the safety and efficacy of the vaccines. Public health efforts to encourage COVID-19 vaccination could use this information to encourage vaccination and overcome vaccine hesitancy. With the authorization of 2 new mRNA COVID-19 vaccines, future studies should investigate the number of physicians in our study who went on to receive the vaccine.

To see this article online, please go to: http://jabfm.org/content/ 34/5/898.full.

\section{References}

1. World Health Organization (WHO). WHO Coronavirus Disease (COVID-19) Dashboard. Available at: https://covid19.who.int/. Accessed December 15, 2020.

2. Centers for Disease Control and Prevention (CDC) Coronavirus 2019. Case of coronavirus (COVID$19)$ in the United States. Available at: https://www. cdc.gov/coronavirus/2019-ncov/cases-updates/casesin-us.html. Accessed December 15, 2020.

3. Ofei-Dodoo S, Loo-Gross C, Kellerman R. Burnout, Depression, Anxiety, and Stress among family physicians in Kansas responding to the COVID-19 pandemic. J Am Board Fam Med. 2021; May-Jun; 34(3):522-530.

4. Stokes EK, Zambrano LD, Anderson KN, et al. Coronavirus Disease 2019 case surveillance United States, January 22-May 30, 2020. MMWR Morb Mortal Wkly Rep 2020;69:759-65.

5. United States Food and Drug Administration (FDA). Pfizer-BioNTech COVID-19 Vaccine. Available at: https://www.fda.gov/emergency-preparedness-andresponse/coronavirus-disease-2019-covid-19/pfizer- biontech-covid-19-vaccine. Accessed December 15, 2020.

6. United States Food and Drug Administration (FDA). FDA Takes Additional Action in Fight Against COVID-19 By Issuing Emergency Use Authorization for Second COVID-19 Vaccine. Available at: https:// www.fda.gov/news-events/press-announcements/fdatakes-additional-action-fight-against-covid-19-issuingemergency-use-authorization-second-covid. Accessed December 18, 2020.

7. Omer SB, Salmon DA, Orenstein WA, DeHart MP, Halsey N. Vaccine refusal, mandatory immunization, and the risks of vaccine-preventable diseases. N Engl J Med 2009;360:1981-8.

8. Dubé E, Vivion M, Sauvageau C, Gagneur A, Gagnon R, Guay M. "Nature does things well, why should we interfere?": vaccine hesitancy among mothers. Qual Health Res 2016;26:411-25.

9. Grandahl M, Oscarsson M, Stenhammar C, Nevéus T, Westerling R, Tydén T. Not the right time: why parents refuse to let their daughters have the human papillomavirus vaccination. Acta Paediatr 2014;103:436-41.

10. Luthy KE, Beckstrand RL, Meyers CJ. Common perceptions of parents requesting personal exemption from vaccination. J Sch Nurs 2013;29:95-103.

11. Harmsen IA, Mollema L, Ruiter RA, Paulussen TG, de Melker HE, Kok G. Why parents refuse childhood vaccination: a qualitative study using online focus groups. BMC Public Health 2013;13:1183.

12. Kaiser Family Foundation. KFF COVID-19 Vaccine Monitor: December 2020. Available at: https://www. kff.org/coronavirus-covid-19/report/kff-covid19-vaccine-monitor-december-2020/. Accessed January 11, 2021.

13. Shen SC, Dubey V. Addressing vaccine hesitancy: clinical guidance for primary care physicians working with parents. Can Fam Physician 2019;65:175-81.

14. Chung Y, Schamel J, Fisher A, Frew PM. Influences on immunization decision-making among US parents of young children. Matern Child Health J 2017;21:2178-87.

15. Freed GL, Clark SJ, Butchart AT, Singer DC, Davis MM. Sources and perceived credibility of vaccine-safety information for parents. Pediatrics 2011 May;127 Suppl 1:S107-12.

16. Creswell JW. Mapping the developing landscape of mixed methods research. In: Tashakkori A, Teddlie C (Eds.). Sage Handbook Of Mixed Methods in Social \& Behavioral Research, 2nd ed. Thousand Oaks, CA: Sage; 2010: 45-68.

17. Dyrbye LN, West CP, Satele D, et al. Burnout among U.S. medical students, residents, and early career physicians relative to the general U.S. population. Acad Med 2014;89:443-51.

18. American Association for Public Opinion Research. Standard Definitions: Final Dispositions of Case Codes and Outcome Rates for Surveys. Available at: https://www.esomar.org/what-we-do/code-guidelines/ 
AAPOR-Standard-Definitions-Final-Dispositions-ofCase-Codes-and-Outcome-Rates-for-Surveys. Accessed December 18, 2020.

19. Ofei-Dodoo S, Kellerman R, Gilchrist K, Casey EM. Burnout and Quality of Life among Active Member Physicians of the Medical Society of Sedgwick County.kjm 2019 May 15;12:33-9.

20. Statistics Kingdom. Chi-square Statistical power calculator. Available at: Available at: http://www. statskingdom.com/34test_power_chi2.html. Accessed December 18, 2020.

21. Kim HY. Statistical notes for clinical researchers: Chi-squared test and Fisher's exact test. Restor Dent Endod 2017;42:152-5.

22. Ofei-Dodoo S, Kellerman R, Nilsen K, Nutting R, Lewis D. Family physicians' perceptions of electronic cigarettes in tobacco use counseling. J Am Board Fam Med 2017;30:448-59.

23. Ofei-Dodoo S, Callaway P, Engels K. Prevalence and etiology of burnout in a community-based graduate medical education system: a mixed-methods study. Fam Med 2019;51:766-71.

24. Miller WL, Crabtree BF. Clinical Research. In: Denzin NK, Lincoln YS (Eds.). Handbook of Qualitative Research. Thousand Oaks, CA: Sage, 1994, pp. 340-52. ISBN: 1483349802.

25. Ofei-Dodoo S, Wipperman J, Nutting R, Gilchrist $\mathrm{K}$, Kellerman R. Changes in family physicians' perceptions of electronic cigarettes in tobacco use counseling between 2016 and 2019. KJM 2020;13:311-7.

26. Data Star, Inc. What Every Researcher Should Know About Statistical Significance. 2008. Available at: http://www.surveystar.com/startips/oct2008.pdf. Accessed December 18, 2020.

27. Lin Y, Hu Z, Zhao Q, Alias H, Danaee M, Wong LP. Understanding COVID-19 vaccine demand and hesitancy: a nationwide online survey in China. PLoS Negl Trop Dis 2020;14:e0008961.

28. Schmid P, Rauber D, Betsch C, Lidolt G, Denker ML. Barriers of influenza vaccination intention and behavior - a systematic review of influenza vaccine hesitancy, 2005-2016. PLoS One 2017;12:e0170550.

29. Mayo Clinic. COVID-19 vaccines: Get the facts. Available at: https://www.mayoclinic.org/diseasesconditions/coronavirus/in-depth/coronavirus-vaccine/ art-20484859. Accessed January 8, 2021.

30. Centers for Disease Control and Prevention. Facts about COVID-19 Vaccines. Available at: https:// www.cdc.gov/coronavirus/2019-ncov/vaccines/facts. html. Accessed January 8, 2021.

31. Peiris M, Leung GM. What can we expect from first-generation COVID-19 vaccines? Lancet 2020;396:1467-9.

32. Centers for Disease Control and Prevention. Ensuring the Safety of COVID-19 Vaccines in the United States. Available at: https://www.cdc.gov/ coronavirus/2019-ncov/vaccines/safety.html. Accessed January 8, 2021.

33. Ng K, Poon BH, Kiat Puar TH, et al. COVID-19 and the risk to health care workers: a case report. Ann Intern Med 2020;172:766-7.

34. Walsh EE, Frenck RW, Jr, Falsey AR, et al. Safety and immunogenicity of two RNA-based Covid-19 vaccine candidates. N Engl J Med 2020;383:2439-50.

35. Baden LR, El Sahly HM, Essink B, et al. Efficacy and safety of the mRNA-1273 SARS-CoV-2 vaccine. [published online ahead of print, $2020 \mathrm{Dec}$ 30]. N Engl J Med 2021;384:403-16.

36. Oliver S, Gargano J, Marin M, et al. The Advisory Committee on Immunization Practices' Interim Recommendation for Use of Moderna COVID-19 Vaccine — United States, December 2020. MMWR Morb Mortal Wkly Rep 2021;69:1653-6.

37. Center for Disease Control and Prevention (CDC). Vaccination Considerations for People who are Pregnant or Breastfeeding. Available at: https:/www.cdc.gov/coronavirus/2019-ncov/vaccines/ recommendations/pregnancy.html. Accessed January $8,2021$.

38. American College of Obstetrics and Gynecology. Vaccinating Pregnant and Lactating Patients Against COVID-19, December 2020. Available at: https:// www.acog.org/clinical/clinical-guidance/practiceadvisory/articles/2020/12/vaccinating-pregnant-andlactating-patients-against-covid-19. Accessed January 8, 2021 .

39. Society for Maternal-Fetal Medicine. Experts in High-Risk Pregnancy Respond to the FDA's Decision to Offer the Newly Approved COVID-19 Vaccine to Pregnant and Lactating People: Healthcare Workers Among the First Expected to Be Impacted. December 2020. Available at: https:// s3.amazonaws.com/cdn.smfm.org/media/2632/FDA_ final.pdf. Accessed January 8, 2021.

40. Dror AA, Eisenbach N, Taiber S, et al. Vaccine hesitancy: the next challenge in the fight against COVID-19. Eur J Epidemiol 2020;35:775-9.

41. Karlsson U, Fraenkel CJ. Covid-19: risks to healthcare workers and their families. BMJ 2020;371:m3944.

42. Sim MR. The COVID-19 pandemic: major risks to healthcare and other workers on the front line. Occup Environ Med 2020;77:281-2.

43. Roush SW, Murphy TV, Vaccine-Preventable Disease Table Working Group. Historical comparisons of morbidity and mortality for vaccine-preventable diseases in the United States. JAMA 2007;298:2155-63.

44. Pandolfi F, Franza L, Todi L, et al. The importance of complying with vaccination protocols in developed countries: "Anti-Vax" hysteria and the spread of severe preventable diseases. Curr Med Chem 2018;25:6070-81. 


\section{Appendix. Survey of Family Physicians and mRNA COVID-19 Vaccines}

1. Have you ever had a positive COVID-19 test or had a physician diagnose you with COVID-19?
a. Yes
b. No
c. I don't know

2. How concerned are you about becoming infected with COVID-19?
a. Extremely concerned
b. Moderately concerned
c. Somewhat concerned
d. Slightly concerned
e. Not at all concerned

3. Do you intend to be vaccinated with a United States Food and Drug Administration (FDA) approved COVID-19 vaccine?
i. Yes
ii. Maybe
iii. No

a. Please explain why you intend to be vaccinated with the FDA approved COVID-19 vaccine

b. Please explain why you may not receive the FDA approved COVID-19 vaccine

c. Please explain why you will not receive the FDA approved COVID-19 vaccine

4. How concerned are you about your family becoming infected with COVID-19?
a. Extremely concerned
b. Moderately concerned
c. Somewhat concerned
d. Slightly concerned
e. Not at all concerned

5. Will you recommend an FDA approved vaccine to your family?
i. Yes
ii. Maybe
iii. No

a. Please explain why you may not recommend the FDA approved COVID-19 vaccine to your family

b. Please explain why you will not recommend the FDA approved COVID-19 vaccine to your family

6. How concerned are you about your patients becoming infected with COVID-19?

a. Extremely concerned

b. moderately concerned

c. Somewhat concerned

d. Slightly concerned

e. Not at all concerned

7. Will you recommend an FDA approved COVID-19 vaccine to your patients?
i. Yes
ii. Maybe
iii. No

a. Please explain why you may not recommend the FDA approved COVID-19 vaccine to your patients

b. Please explain why you will not recommend the FDA approved COVID-19 vaccine to your patients

8. I'm a...
i. faculty physician
ii. practicing physician
iii. resident physician

a. I'm a...

i. PGY 1 resident

ii. PGY 1 resident

iii. PGY 1 resident

b. How many years have you been in practice since residency?

9. What year were you born?

10. What is your biological sex at birth?

a. Male

b. Female

11. In which Kansas county do you primarily practice? 